\title{
The Influence of the Grapevine Bacterial and Fungal Endophytes on Biomass Accumulation and Stilbene Production by the In Vitro Cultivated Cells of Vitis amurensis Rupr.
}

\author{
Olga A. Aleynova *(D), Andrey R. Suprun (D), Nikolay N. Nityagovsky, Alexandra S. Dubrovina $(\mathbb{D}$ \\ and Konstantin V. Kiselev
}

check for updates

Citation: Aleynova, O.A.; Suprun, A.R.; Nityagovsky, N.N.; Dubrovina, A.S.; Kiselev, K.V. The Influence of the Grapevine Bacterial and Fungal Endophytes on Biomass Accumulation and Stilbene Production by the In Vitro Cultivated Cells of Vitis amurensis Rupr.. Plants 2021, 10, 1276. https://doi.org/ $10.3390 /$ plants10071276

Academic Editor: George Lazarovits

Received: 13 May 2021

Accepted: 21 June 2021

Published: 23 June 2021

Publisher's Note: MDPI stays neutral with regard to jurisdictional claims in published maps and institutional affiliations.

Copyright: (c) 2021 by the authors. Licensee MDPI, Basel, Switzerland. This article is an open access article distributed under the terms and conditions of the Creative Commons Attribution (CC BY) license (https:/ / creativecommons.org/licenses/by/ $4.0 /)$.
Laboratory of Biotechnology, Federal Scientific Center of the East Asia Terrestrial Biodiversity, Far Eastern Branch of the Russian Academy of Sciences, 690022 Vladivostok, Russia; SUPRUN@biosoil.ru (A.R.S.); niknit1996@gmail.com (N.N.N.); dubrovina@biosoil.ru (A.S.D.); kiselev@biosoil.ru (K.V.K.)

* Correspondence: aleynova@biosoil.ru; Tel.: +7-4232-310718; Fax: +7-4232-310193
Abstract: Plant endophytes are known to alter the profile of secondary metabolites in plant hosts. In this study, we identified the main bacterial and fungal representatives of the wild grape Vitis amurensis Rupr. microbiome and investigated a cocultivation effect of the 14 endophytes and the V. amurensis cell suspension on biomass accumulation and stilbene biosynthesis. The cocultivation of the V. amurensis cell culture with the bacteria Agrobacterium sp., Bacillus sp., and Curtobacterium sp. for 2 weeks did not significantly affect the accumulation of cell culture fresh biomass. However, it was significantly inhibited by the bacteria Erwinia sp., Pantoea sp., Pseudomonas sp., and Xanthomonas sp. and fungi Alternaria sp., Biscogniauxia sp., Cladosporium sp., Didymella sp. 2, and Fusarium sp. Cocultivation of the grapevine cell suspension with the fungi Didymella sp. 1 and Trichoderma sp. resulted in cell death. The addition of endophytic bacteria increased the total stilbene content by 2.2-5.3 times, while the addition of endophytic fungi was more effective in inducing stilbene accumulation by 2.6-16.3 times. The highest content of stilbenes in the grapevine cells cocultured with endophytic fungi was 13.63 and $13.76 \mathrm{mg} / \mathrm{g}$ of the cell dry weight (DW) after cultivation with Biscogniauxia sp. and Didymella sp. 2, respectively. The highest content of stilbenes in the grapevine cells cocultured with endophytic bacteria was $4.49 \mathrm{mg} / \mathrm{g}$ DW after cultivation with Xanthomonas sp. The increase in stilbene production was due to a significant activation of phenylalanine ammonia lyase $(P A L)$ and stilbene synthase (STS) gene expression. We also analyzed the sensitivity of the selected endophytes to eight antibiotics, fluconazole, and trans-resveratrol. The endophytic bacteria were sensitive to gentamicin and kanamycin, while all selected fungal strains were resistant to fluconazole with the exception of Cladosporium sp. All endophytes were tolerant of trans-resveratrol. This study showed that grape endophytes stimulate the production of stilbenes in grape cell suspension, which could further contribute to the generation of a new stimulator of stilbene biosynthesis in grapevine or grape cell cultures.

Keywords: endophyte; bacteria; fungi; cell culture; grape; Vitis amurensis; resveratrol; stilbene; stilbene synthase (STS); phenylalanine ammonia lyase (PAL)

\section{Introduction}

Endophytes are microorganisms that inhabit the tissues of living plants without any negative consequences for plant growth and development. Plant endophytes are usually presented by fungi and bacteria and less often algae and viruses [1]. In recent years, plant endophytes have attracted more attention from researchers in terms of their diversity and application for improving plant properties or plant disease protection. Endophytes inhabiting grapes are no exception. Grapes are one of the most important fruit crops in the 
world but are largely affected by a large number of pathogens that cause diseases before and after harvest, affecting production, processing, exports, and the quality of the fruit.

There are many studies devoted to the microbiome of grapes of the European grape group [2-4]. It has been shown that some grape endophytes are able to prevent infection, inhibit grape pathogens, increase abiotic stress resistance, and increase the content of nutrients in berries [5-8]. Additionally, it has been found that exposure of grape cells to endophytic fungi (Alternaria alternate and Epicoccum nigrum) and a dual culture system differentially affected total anthocyanin concentrations and phenylalanine ammonia lyase activities [9]. It has also been shown that fungal endophytes form new metabolite patterns in grape cells during double culture and showed fungal strain specificity [10].

While there is a number of studies that examined grapevines of European grapes (Vitis vinifera), there is not enough information about the endophytes of the Asian group of grapes, e.g., Vitis amurensis Rupr. This species is of interest because it grows in the wild, and it is a leader in terms of the content of valuable biologically active substances (stilbenes) among grape species. Furthermore, V. amurensis exhibits a high resistance to low temperatures and microbial diseases [11,12]. Knowledge on the endophytic microorganisms inhabiting the highly resistant grapevine $V$. amurensis could help develop new approaches for prevention of the emergence and spread of grape diseases.

$V$. amurensis is highly resistant to such widespread grapevine diseases as powdery mildew, the pathogen Oidium tuckeri (a teleomorph of Uncinulanecator) [13], grape white rot, and anthracnose [14]. The biologically active compounds found in the grape stem of $V$. amurensis are capable of suppressing pathogenic bacteria, such as Streptococcus mutans and Streptococcus sanguis [15]. Chinese scientists have described a new pathogenic fungus, Fusarium avenaceum, which affects the fruits of V. amurensis [16]. Recently, it has been shown that the endophytic fungus Albifimbria verrucaria isolated from Amur grapes was active against Botrytis cinerea, causing gray mold disease in grapes [17]. To the best of our knowledge, there are no other studies analyzing the microorganisms inhabiting and affecting $V$. amurensis.

In the present work, we focused on the influence of basic endophytic bacteria and fungi of wild grapes (V. amurensis) on the biosynthesis of stilbenes in $V$. amurensis cell suspension culture. Stilbenes are a relatively small group of naturally occurring phenolic compounds found in a number of unrelated plant families, such as peanuts (Fabaceae), pine (Pinaceae), or grapes (Vitaceae). Grapevine is a leader in the content of resveratrol among other plants. The most famous stilbene is trans-resveratrol or $t$-resveratrol $\left(3,5,4^{\prime}\right.$-trihydroxytrans-stilbene), which is the main precursor in the biosynthesis of other stilbenes [18] and possesses a wide spectrum of biological activities [19]. It has been established that $t$-resveratrol is able to prevent the occurrence and development of cardiovascular and oncological diseases, exhibits antiallergic effects, and slows down the aging process [19,20]. Additionally, stilbenes are important for plant protection against microbial pathogens [21]. In this research, we studied the effect of the main endophytic bacteria (Agrobacterium sp., Bacillus sp., Curtobacterium sp., Erwinia sp., Pantoea sp., Pseudomonas sp., Xanthomonas sp.) and endophytic fungi (Alternaria sp., Didymella sp. 1, Didymella sp. 2, Cladosporium sp., Fusarium sp., Trichoderma sp., and Biscogniauxia sp.) on the cell growth, production, and biosynthesis of stilbenes in $V$. amurensis cell culture.

\section{Results}

\subsection{Identification of V. amurensis Endophytes}

We selected and identified the main representatives of the microbiome of $V$. amurensis. Analysis of the nucleotide sequences of $16 S$ rRNA genes (for bacteria) and sequences of internal transcribed spacers ITS1 (for fungi) revealed that the isolated strains are representatives of the endophytic bacteria genera Agrobacterium sp., Bacillus sp., Curtobacterium sp., Erwinia sp., Pantoea sp., Pseudomonas sp., and Xanthomonas sp., as well as endophytic fungi genera Alternaria sp., Didymella sp. 1, Didymella sp. 2, Cladosporium sp., Fusarium sp., Trichoderma sp., and Biscogniauxia sp. (Table 1). 
Table 1. Characteristics of the bacteria and fungi strains isolated from Vitis amurensis grape microbiome based on $16 S \mathrm{rRNA}$ (bacteria) gene or internal transcribed spacers ITS1 (fungi) sequences. The resulting nucleotide sequences were collected using the Staden Package program. The percentage identities of the collected nucleotide sequences were determined using NCBI BLAST (http:/ / blast.ncbi.nlm.nih.gov; accessed date 11 May 2021) and the Nucleotide Blast (nucleotide-nucleotide BLAST) algorithm.

\begin{tabular}{|c|c|c|c|c|}
\hline № & Used Gene & Genus and Sequence ID & The Close Species and Sequence ID & Percent Identity \\
\hline 1 & $16 S r R N A$ & Agrobacterium (MZ424738) & Agrobacterium rubi (MN752429.1) & $99.17 \%$ \\
\hline 2 & $16 S$ rRNA & Bacillus (MZ424739) & Bacillus thuringiensis (KU179338.1) & $100 \%$ \\
\hline 3 & $16 S$ rRNA & Curtobacterium (MZ424740) & $\begin{array}{c}\text { Curtobacterium flaccumfaciens } \\
\text { (AJ310414.1) }\end{array}$ & $100 \%$ \\
\hline 4 & $16 S r R N A$ & Erwinia (MZ424741) & Erwinia billingiae (KM408608.1) & $100 \%$ \\
\hline 5 & $16 S r R N A$ & Pantoae (MZ424742) & Pantoea agglomerans (MT605813.1) & $99.75 \%$ \\
\hline 6 & $16 S r R N A$ & Pseudomonas (MZ424743) & $\begin{array}{c}\text { Pseudomonas alkylphenolica } \\
\text { (MN813762.1) }\end{array}$ & $99.89 \%$ \\
\hline 7 & $16 S r R N A$ & Xanthomonas (MZ424744) & Xanthomonas campestris (MN108237.1) & $99.13 \%$ \\
\hline 8 & ITS1 & Alternaria (MZ427922) & Alternaria tenuissima (KF308883.1) & $100 \%$ \\
\hline 9 & ITS1 & Biscogniauxia (MZ427923) & Biscogniauxia maritima (MN341558.1) & $100 \%$ \\
\hline 10 & ITS1 & Cladosporium (MZ427924) & $\begin{array}{c}\text { Cladosporium perangustum } \\
\text { (MT645918.1) }\end{array}$ & $100 \%$ \\
\hline 11 & ITS1 & Didymella (MZ427925) & Didymella negriana (MK100201.1) & $100 \%$ \\
\hline 12 & ITS1 & Didymella (MZ427926) & Didymella pinodella (KX869956.1) & $100 \%$ \\
\hline 13 & ITS1 & Fusarium (MZ427927) & Fusarium tricinctum (MT446111.1) & $100 \%$ \\
\hline 14 & ITS1 & Trichoderma (MZ427928) & Trichoderma harzianum (MT422092.1) & $98.97 \%$ \\
\hline
\end{tabular}

2.2. The Influence of V. amurensis Endophytes on the Fresh Biomass Accumulation in V. amurensis Cell Culture

We added the selected endophytic bacteria and fungi to a cell suspension culture of $V$. amurensis (V7) and estimated the accumulation of fresh biomass and stilbene content. The addition of Agrobacterium sp., Bacillus sp., and Curtobacterium sp. did not significantly affect the accumulation of fresh biomass of the grapevine cell suspension culture after 2 weeks of cocultivation (Figure 1). However, the addition of bacteria Erwinia sp., Pantoea sp., Pseudomonas sp., and Xanthomonas sp. and fungi Alternaria sp., Biscogniauxia sp., Cladosporium sp., Didymella sp. 2, and Fusarium sp. significantly inhibited the accumulation of the cell culture fresh biomass by 1.7-2.7 times (Figure 1). Cocultivation of the V7 cells with the endophytic fungi Didymella sp. 1 and Trichoderma sp. resulted in cell death (Figure 1).

2.3. The Effect of the Endophytic Bacteria and Fungi on Stilbene Content in the V. amurensis Cell Suspension

High-performance liquid chromatography (HPLC) analysis revealed that the total stilbene content in the V7 cell suspension increased by 2.2-16 times after the addition of endophytes (Figure 2). The highest stilbene content was $2.2-4.5 \mathrm{mg} / \mathrm{g}$ DW, which occurred under the influence of bacteria Curtobacterium sp., Erwinia sp., Pantoae sp., Pseudomonas sp., and Xanthomonas sp. The highest stilbene content in the V7 cell culture after bacterial treatment was $4.5 \mathrm{mg} / \mathrm{g}$ DW, which occurred during cocultivation with bacteria Xanthomonas sp. (Figure 2). However, a more significant increase in stilbene content to $6.95-13.76 \mathrm{mg} / \mathrm{g}$ DW was detected after culture cocultivation with the endophytic fungi Biscogniauxia sp., Cladosporium sp., Didymella sp. 1, and Didymella sp. 2 (Figure 2). 


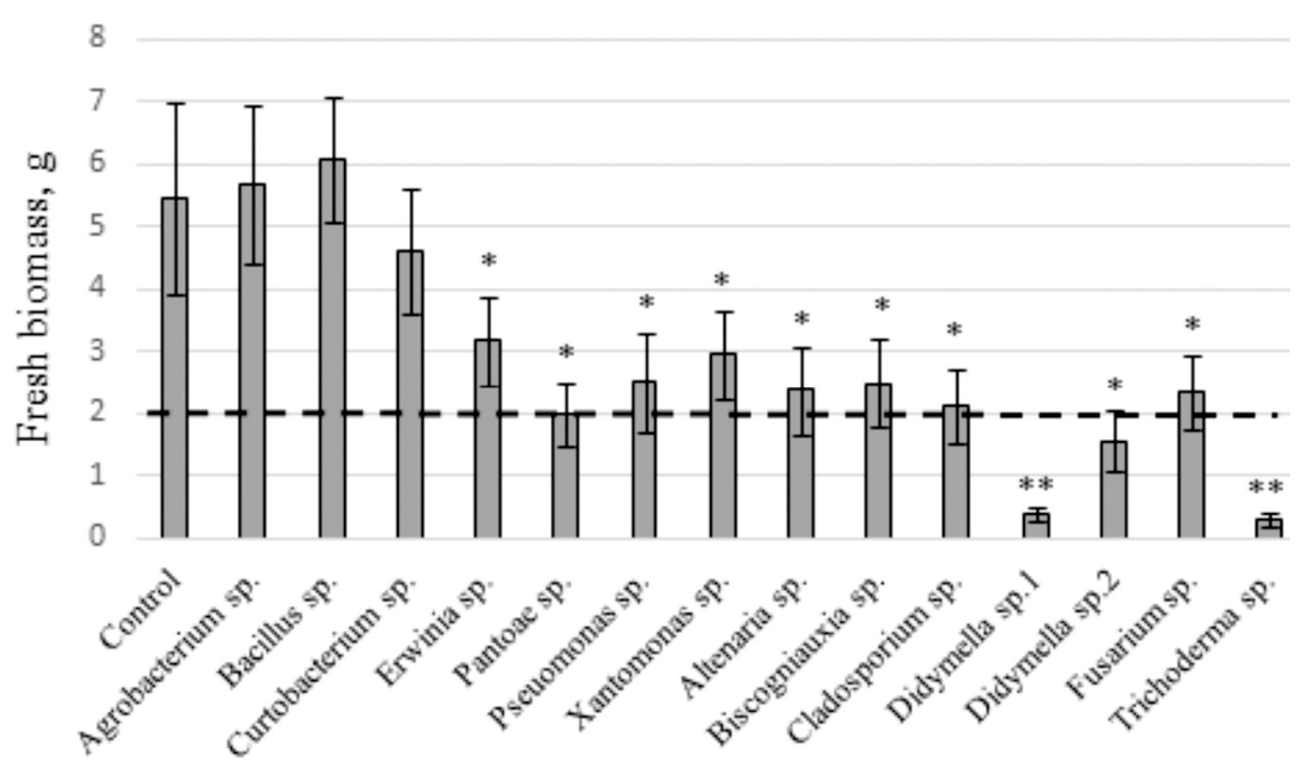

Figure 1. Accumulation of fresh biomass in the V7 cell suspension culture of Vitis amurensis after one week of cocultivation with the $V$. amurensis endophytic bacteria or fungi. The dotted line depicts an inoculum mass of 2 g. ${ }^{*} p<0.05 ;{ }^{* *} p<0.01$ versus values of fresh biomass accumulated in the V7 cell under the control conditions without bacteria and fungi.

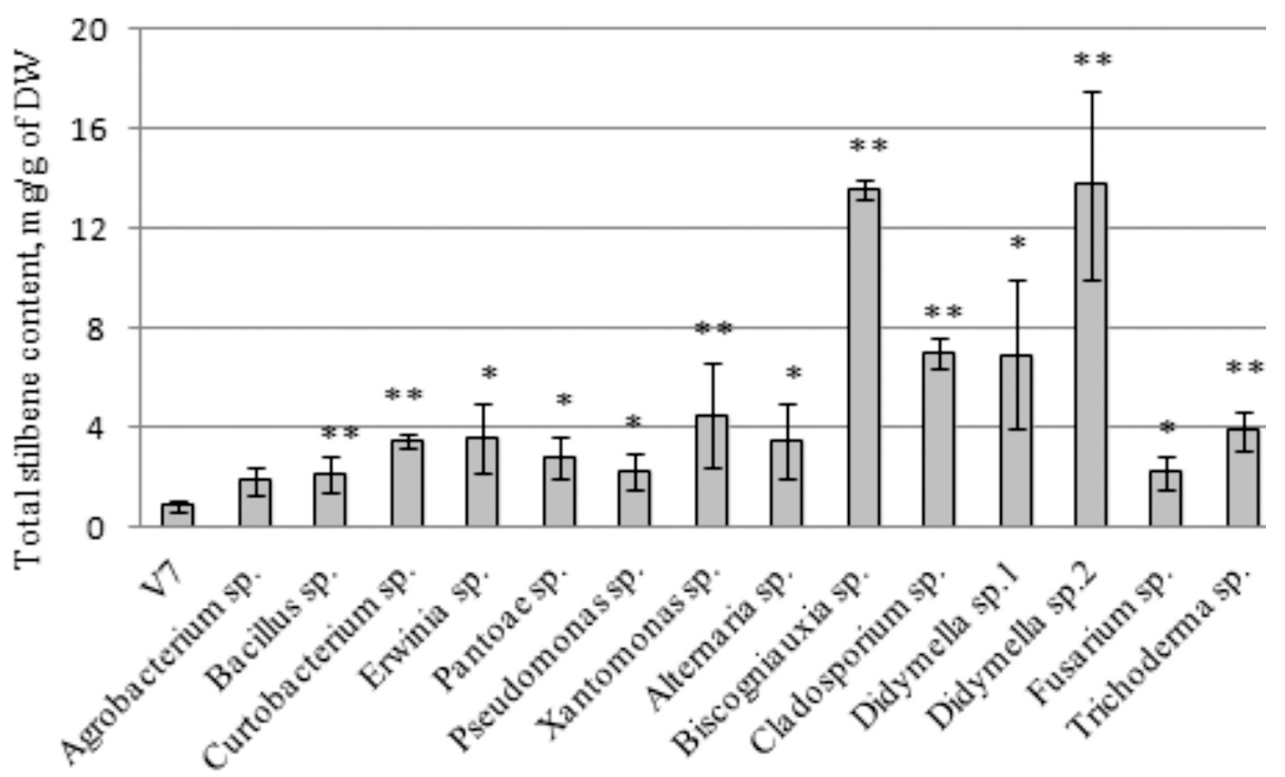

Figure 2. The total stilbene content (mg/g of the cell dry weight (DW)) in the V7 cell suspension culture of Vitis amurensis V7 after 3 days cocultivation with endophytic bacteria or fungi. ${ }^{*} p<0.05$; ** $p<0.01$ versus values of stilbene accumulation in the V7 cell cultivated under control conditions without bacteria and fungi.

Then, we analyzed the composition and content of individual stilbenes in the culture samples after cocultivation with the endophytes (Table 2). A distinctive feature of the treatment with bacteria and fungi was that the relative content of glycosylated stilbenes decreased significantly in the samples. In the control cell culture, the total content of diglucoside trans-resveratrol, trans-piceid, and cis-piceid was about $64 \%$ of the total amount of stilbenes, while it was $28-57 \%$ when treated with bacteria and only $13-31 \%$ when treated with fungi (Table 2). 


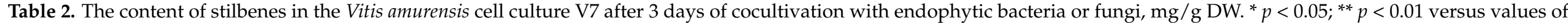
stilbene accumulation in the V7 cell cultivated under control conditions without bacteria and fungi.

\begin{tabular}{|c|c|c|c|c|c|c|c|c|}
\hline & $\begin{array}{c}\text { Di-glucoside } \\
\text { trans-Resveratrol }\end{array}$ & trans-Piceid & trans-Resveratrol & epsilon-Viniferin & delta-Viniferin & cis-Resveratrol & cis-Piceid & trans-Piceatannol \\
\hline V7, Control & $0.432 \pm 0.135$ & $0.104 \pm 0.022$ & $0.029 \pm 0.008$ & $0.024 \pm 0.007$ & $0.255 \pm 0.077$ & $0.0004 \pm 0.0001$ & $0.0103 \pm 0.0061$ & 0 \\
\hline Agrobacterium sp. & $0.583 \pm 0.167$ & $0.136 \pm 0.055$ & $0.140^{* *} \pm 0.036$ & $0.279 * \pm 0.129$ & $0.802 * \pm 0.240$ & $0.0010 \pm 0.0004$ & $0.0017 \pm 0.0015$ & 0 \\
\hline Bacillus sp. & $0.823 \pm 0.322$ & $0.291^{* *} \pm 0.053$ & $0.141^{* *} \pm 0.049$ & $0.190^{* *} \pm 0.068$ & $0.575 \pm 0.213$ & $0.0011 * \pm 0.0004$ & $0.0693 \pm 0.0561$ & $0.0014 \pm 0.0014$ \\
\hline $\begin{array}{l}\text { Curtobacterium } \\
\text { sp. }\end{array}$ & $3.447^{*} \pm 0.247$ & $0.348^{* *} \pm 0.082$ & $0.181^{* *} \pm 0.043$ & $0.131^{* *} \pm 0.024$ & $1.412^{* *} \pm 0.415$ & $0.0015^{* *} \pm 0.0003$ & $0.1025^{* *} \pm 0.0674$ & 0 \\
\hline Erwinia sp. & $0.860 \pm 0.350$ & $0.243 \pm 0.078$ & $0.364^{*} \pm 0.201$ & $1.154^{* *} \pm 0.535$ & $0.940 * \pm 0.333$ & $0.0018 * \pm 0.0008$ & $0.0143 \pm 0.0059$ & $0.0249 * \pm 0.0228$ \\
\hline Pseudomonas sp. & $0.486 \pm 0.232$ & $0.230 \pm 0.094$ & $0.167^{* *} \pm 0.047$ & $0.440^{* *} \pm 0.158$ & $0.861 * \pm 0.304$ & $0.0016 \pm 0.0007$ & $0.0084 \pm 0.0045$ & $0.0245 \pm 0.0245$ \\
\hline Xantomonas sp. & $4.491 * \pm 2.124$ & $\begin{array}{l}0.364^{* *} \\
\pm 0.148\end{array}$ & $0.433^{* *} \pm 0.012$ & $0.372^{* *} \pm 0.220$ & $1.958 * \pm 1.605$ & $0.0022^{* *} \pm 0.0001$ & $0.0268 \pm 0.0268$ & 0 \\
\hline Alternaria sp. & $0.620 \pm 0.255$ & $0.239 \pm 0.098$ & $0.338^{* *} \pm 0.117$ & $1.292^{* *} \pm 0.586$ & $0.941 \pm 0.469$ & $0.0029 \pm 0.0013$ & $0.0501 \pm 0.0326$ & $0.0046 \pm 0.0046$ \\
\hline Biscogniauxia sp. & $1.265^{*} \pm 0.206$ & $0.477^{* *} \pm 0.106$ & $2.861^{* *} \pm 0.415$ & $3.952 * * \pm 0.664$ & $4.981^{* *} \pm 0.335$ & $0.0035 * \pm 0.0002$ & $0.0910 \pm 0.0162$ & 0 \\
\hline Cladosporium sp. & $1.258^{* *} \pm 0.178$ & $\begin{array}{l}0.346^{* *} \\
\pm 0.082\end{array}$ & $0.882^{* *} \pm 0.136$ & $2.964^{* *} \pm 0.132$ & $1.504 * \pm 0.866$ & $0.0040^{* *} \pm 0.0002$ & $0.0216 \pm 0.0125$ & 0 \\
\hline Didymella sp. 1 & $1.035 \pm 0.667$ & $0.427^{*} \pm 0.339$ & $1.180 * \pm 1.130$ & $2.082^{* *} \pm 1.872$ & $2.222 * \pm 2.060$ & $0.002 \pm 0.002$ & 0 & 0 \\
\hline Fusarium sp. & $0.487 \pm 0.236$ & $0.147 \pm 0.078$ & $0.171 * \pm 0.073$ & $0.614^{* *} \pm 0.163$ & $0.700 * \pm 0.229$ & $0.0173^{* *} \pm 0.0165$ & $0.0295 \pm 0.0184$ & 0 \\
\hline Trichoderma sp. & $0.682 \pm 0.024$ & $0.099 \pm 0.001$ & $0.127^{* *} \pm 0.015$ & $0.195^{* *} \pm 0.079$ & $2.706^{* *} \pm 0.884$ & $0.0025^{* *} \pm 0.0004$ & $0.0465 \pm 0.0268$ & $0.0094 * \pm 0.0054$ \\
\hline
\end{tabular}


The second feature was a drastic increase in the content of trans-resveratrol after the addition of bacteria and fungi by 4.8-16.4 and 4.9-98.5 times, respectively. The highest transresveratrol content was $2.9 \mathrm{mg} / \mathrm{g}$ DW, which was detected in grapevine cells cultivated with an endophytic fungus, Biscogniauxia sp. (Table 2). Among the bacteria, the most stimulating effect on the content of trans-resveratrol was exerted by the cultivation with bacteria Pantoae sp. leading to a content of $0.5 \mathrm{mg} / \mathrm{g}$ DW (Table 2). The content of viniferins (epsilon-viniferin and delta-viniferin) was also substantially increased after the addition of bacteria and fungi by 2.8-8.4 and 4.8-32.1 times, respectively. For example, when cultured with the endophytic fungus, Biscogniauxia sp., the amount of viniferins reached $9 \mathrm{mg} / \mathrm{g}$ DW, which was $65 \%$ of all detected stilbenes. At the same time, the amount of viniferins in the control V7 cell culture without bacterium or fungi treatment was only $33 \%$ (Table 2).

\subsection{VaPAL and VaSTS Gene Expression in V. amurensis Cells with the Addition of Endophytes}

Then, we analyzed VaPAL and VaSTS gene expression after cocultivation with the endophytic bacteria and fungi. We also analyzed the effect of Agrobacterium sp. on the expression of the VaPAL and VaSTS genes to use it as a negative control, as this bacterium did not significantly increase stilbene content in the grapevine cells. We found that the addition of all selected endophytic fungi led to a significant activation of the VaPAL1VaPAL4 genes by 2.6-44 times compared with untreated cells V7 (Figure 3a). The addition of the endophytic bacteria differently activated the expression of each $V a P A L$ gene. The expression of the VaPAL1-VaPAL3 genes significantly increased by 1.7-17 times after the addition of Erwinia sp. and Pantoae sp. bacteria. The addition of Pantoae sp. significantly increased the expression of VaPAL4 (Figure 3a). The expression of the VaPAL3 gene was significantly increased when the endophytic bacteria Agrobacterium sp. and Pseudomonas sp. were added to the V7 cell culture. The addition of bacteria Xanthomonas sp. significantly increased only the expression of the VaPAL2 gene (Figure 3a).

The expression of VaSTS1-VaSTS5 genes significantly increased after cocultivation with the endophytic bacteria Erwinia sp. and Pantoae sp. and all selected endophytic fungi (Figure 3b,c). The expression of the VaSTS2 gene significantly increased with the addition of all selected bacteria (Figure $3 b$ ). With the addition of all selected endophytes, STS7 gene expression increased most significantly in comparison with other STS genes. The greatest expression of this gene was 32 times higher than in the untreated V7 cells and was observed after the addition of the fungus Biscogniauxia sp. (Figure 3c). The increase in STS8 gene expression was observed with the addition of Pantoae sp. bacteria and fungi Cladosporium sp. and Didymella sp. 2. The addition of Biscogniauxia sp. and Cladosporium sp. fungi significantly increased STS9 and STS10 gene expression. We also observed an increase in the VaSTS10 gene expression after the addition of bacteria Pantoae sp. (Figure 3c).

\subsection{Sensitivity of the Grape Endophytes to Antibiotics, Fluconazole, and Resveratrol}

We tested the sensitivity of the bacteria to antibiotics and to trans-resveratrol, which is stilbene with known antibacterial properties [22,23]. We placed antibiotic-soaked paper disks on plates with bacteria and evaluated the bacterial growth line around the paper disk after 2 days. We observed that gentamicin and kanamycin inhibited the growth of all selected endophytic bacteria (Table 3). Rifampicin also inhibited the growth of all endophytic bacteria, except for Pantoae sp. The growth of Agrobacterium sp. was also suppressed by antibiotics, such as ampicillin, cefotaxime, spectinomycin, and tetracycline. The growth of Erwinia sp. was suppressed by the antibiotic cefotaxime, and the growth of Pseudomonas sp. was suppressed by spectinomycin and tetracycline (Table 3). All endophytic bacteria were resistant to trans-resveratrol (Table 3). 

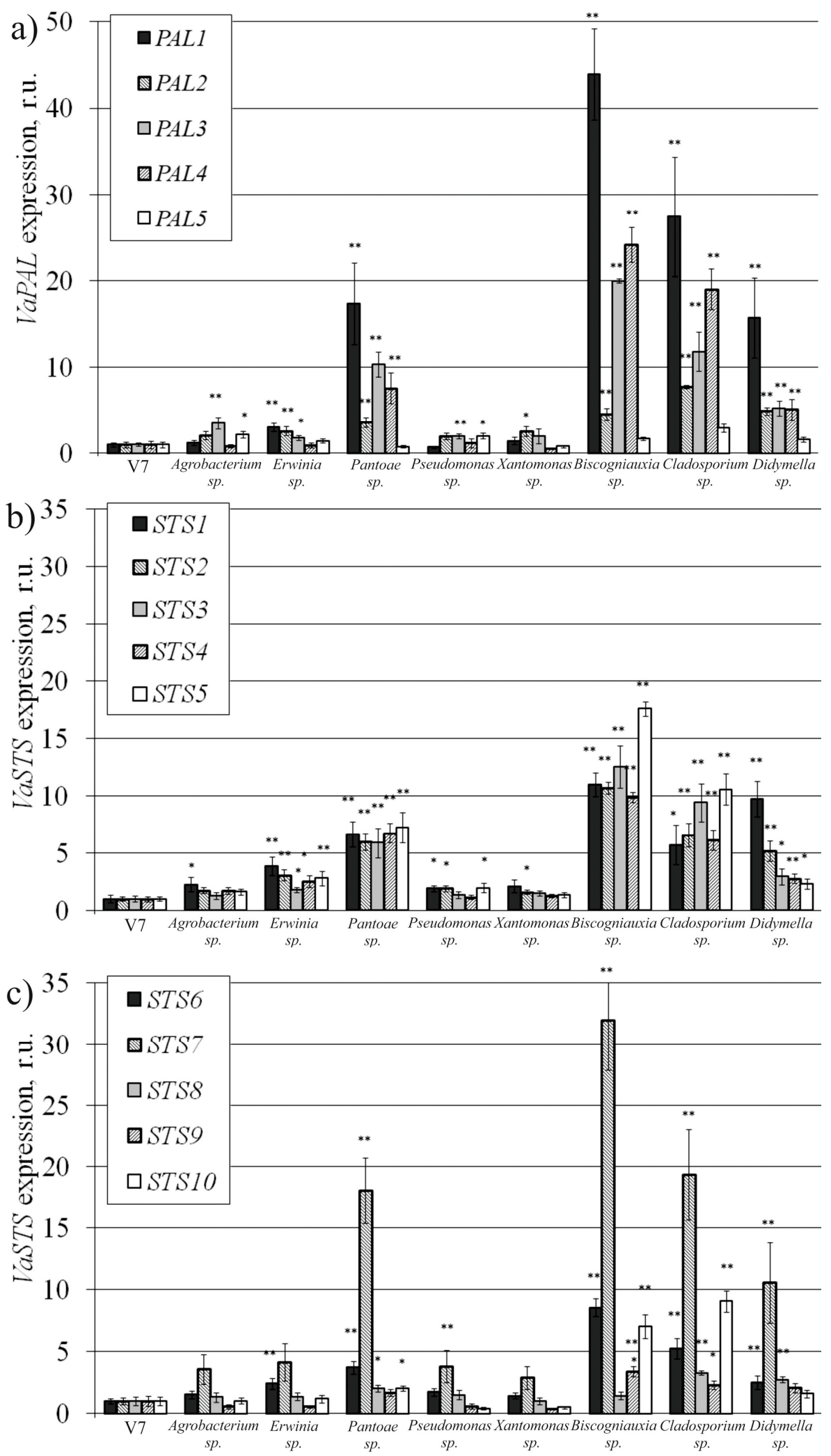

Figure 3. VaPAL (a) and VaSTS (b,c) gene expression in the V7 cell suspension culture of Vitis amurensis after 3 days of cocultivation with the endophytic bacteria Agrobacterium sp., Erwinia sp., Pantoae sp., Pseudomonas sp., Xantomonas sp. or fungi Biscogniauxia sp., Cladosporium sp., and Didymella sp. 2. ${ }^{*} p<0.05 ;{ }^{* *} p<0.01$ versus values of fresh biomass accumulation in the V7 cells cultivated under control conditions without bacteria and fungi. 
Table 3. Analysis of the sensitivity of endophytic bacteria and fungi of Vitis amurensis to antibiotics and trans-resveratrol. The values are given as the distance $(\mathrm{cm})$ from the antibiotic-soaked paper disk to the visible bacterial growth zone. Ap-ampicillin $(50 \mathrm{mg} / \mathrm{L}), \mathrm{Cam}$-chloramphenicol (35 mg/L), Cf-cefotaxime (250 mg/L), Gent—gentamicin (50 mg/L), Km—kanamycin (50 mg/L), $\mathrm{Rf}$-rifampicin $(50 \mathrm{mg} / \mathrm{L}), \mathrm{Sp}$ - spectinomycin $(150 \mathrm{mg} / \mathrm{L})$, Tet-tetracycline $(40 \mathrm{mg} / \mathrm{L})$, Flucfluconazole (50 mg /L), Res-trans-resveratrol (1 mM); n.m.-not measured; * external visible changes of the fungal coloring.

\begin{tabular}{|c|c|c|c|c|c|c|c|c|c|c|}
\hline \multirow[b]{2}{*}{ Genus } & \multicolumn{8}{|c|}{ Antibiotics } & \multirow{2}{*}{ Res. } & \multirow{2}{*}{ Fluc. } \\
\hline & Ap & Cam & $\mathrm{Cf}$ & Gent & $\mathrm{Km}$ & Rf & $S p$ & Tet & & \\
\hline Agrobacterium & 0.3 & 0 & 1 & 1 & 1.2 & 0.5 & 1 & 1.6 & 0 & n.m. \\
\hline Bacillus & 0 & 0 & 0 & 0.6 & 0.5 & 0.6 & 0 & 0 & 0 & n.m. \\
\hline Erwinia & 0 & 0 & 1 & 0.5 & 0.6 & 0.3 & 0 & 0 & 0.2 & n.m. \\
\hline Pantoae & 0 & 0 & 0 & 0.6 & 0.8 & 0 & 0 & 0 & 0 & n.m. \\
\hline Curtobacterium & 0 & 0 & 0 & 0.8 & 1 & 2 & 0 & 0.2 & 0 & n.m. \\
\hline Xantomonas & 0 & 0 & 0 & 0.6 & 0.8 & 0.8 & 0 & 0 & 0 & n.m. \\
\hline Pseudomonas & 0 & 0 & 0 & 0.6 & 0.5 & 0.7 & 0.6 & 0.7 & 0 & n.m. \\
\hline Fusarium & n.m. & n.m. & n.m. & n.m. & n.m. & n.m. & n.m. & n.m. & $0 *$ & $0.1 *$ \\
\hline Alternaria & n.m. & n.m. & n.m. & n.m. & n.m. & n.m. & n.m. & n.m. & $0 *$ & $0.1^{*}$ \\
\hline Didymella-1 & n.m. & n.m. & n.m. & n.m. & n.m. & n.m. & n.m. & n.m. & $0 *$ & $0 *$ \\
\hline Didymella-2 & n.m. & n.m. & n.m. & n.m. & n.m. & n.m. & n.m. & n.m. & $0 *$ & 0 * \\
\hline Trichoderma & n.m. & n.m. & n.m. & n.m. & n.m. & n.m. & n.m. & n.m. & 0 & 0 * \\
\hline Cladosporium & n.m. & n.m. & n.m. & n.m. & n.m. & n.m. & n.m. & n.m. & 0 * & 0.5 \\
\hline Biscogniauxia & n.m. & n.m. & n.m. & n.m. & n.m. & n.m. & n.m. & n.m. & 0 * & $0 *$ \\
\hline
\end{tabular}

The sensitivity of fungi to fluconazole and trans-resveratrol was evaluated in a similar way. Only one fungus, Cladosporium sp., was found to be sensitive to fluconazole (Table 3). The rest of the endophytic fungi changed color when growing on a paper disk soaked in fluconazole, but no visible growth-restriction zone was observed (Table 3). Additionally, all endophytic fungi were resistant to trans-resveratrol (Table 3). The fact that none of the endophytes were inhibited by trans-resveratrol suggests that these are indeed typical endophytes of $V$. amurensis and developed protective mechanisms against this stilbene.

\section{Discussion}

The content of stilbenes in the plant material did not exceed $0.01 \%$ of the dry mass of cells, which could increase the cost of producing stilbenes on an industrial scale. Today, there are many ways in biotechnology to stimulate the biosynthesis of stilbenes, but these approaches are mainly based on using chemicals that are often unfavorable to human health. In recent years, investigation and application of the plant endophytes and endophyte-based preparations have been actively developed to improve crop properties, i.e., abiotic and biotic stress resistance, yield and fruit quality, and the content of valuable secondary metabolites.

To date, several works have been devoted to studying the effect of grape endophytic fungi on the metabolism and performance in grapevine cell cultures. It has been shown that the cocultivation of grape cells with different strains of fungi led to the appearance of new metabolites (from 1 to 11) specific for the strain/genus of endophytic fungi, previously not characterized in grape cell culture [24]. Furthermore, the addition of fungal endophytes to grape cell culture resulted in changed primary and secondary metabolism. The total sugar content, titrated acidity, total soluble protein content, total flavonoids and phenols, and malondialdehyde, as well as the activity of antioxidant enzymes, guaiacol-dependent peroxidase, superoxide dismutase, and $P A L$, were changed [10]. Fungal endophytes can 
produce different elicitors or other signaling molecules, which in turn causes different metabolic changes, so the oxidative response may be a result of a common cell response to the changes in metabolism mediated by endophytes in the host plants [25].

Recently, Chinese scientists found that the addition of endophytic fungi to grape cell culture had different effects on the total concentration of anthocyanins and the activity of $P A L$ in grape cells. When the strains of the fungi Alternaria alternata and Epicoccum nigrum were cocultured with grape cells, the anthocyanin content increased by $74 \%$ and $28 \%$, respectively, while the addition of another strain of $A$. alternata reduced the anthocyanin content by $19 \%$ [9]. Thus, during the cocultivation of grape cells together with fungal endophytes, protective reactions occur in the grape cells leading to metabolic changes in the grape cells.

This study firstly examined the influence of the main representatives of the endophytic bacteria and fungi of wild grape $V$. amurensis on cell growth and the production of resveratrol and its derivatives. The highest total content of stilbenes, particularly trans-resveratrol, was observed in the $V$. amurensis cell culture with the addition of the fungi Biscogniauxia sp., Cladosporium sp., and Didymella sp. 2, which correlated with a significant increase in the expression of most analyzed PAL and STS genes. The stilbene level reached $13.8 \mathrm{mg} / \mathrm{g}$ DW (or $1.35 \%$ DW) after cocultivation with endophytic fungi and $4.5 \mathrm{mg} / \mathrm{g}$ DW (or $0.45 \%$ DW) after cocultivation with endophytic bacteria. This significant increase was due to a strong increase in the biosynthesis of trans-resveratrol and its oligomers, viniferins.

It is important to note that this resulting stilbene level was one of the highest observed thus far for plant cell cultures [26]. For example, at $18 \mathrm{~h}$ after UV-C treatment, the stilbene content in Arachis hypogaea callus cultures reached $0.017 \mathrm{mg} / \mathrm{g}$ FW or approximately $0.3 \mathrm{mg} / \mathrm{g}$ DW [27]. The culture that had been inoculated with the plant pathogen Botryodiplodia theobromae stilbene content reached $0.023 \mathrm{mg} / \mathrm{g}$ FW or approximately $0.5 \mathrm{mg} / \mathrm{g}$ DW [28]. In V. vinifera cell suspension culture, the stilbene level was $2.1 \mathrm{mg} / \mathrm{g}$ DW at 2 days after UV-C and $100 \mu \mathrm{M}$ MeJa treatment [29].

The reached stilbene content in the present investigation was higher than the stilbene content in the leaves of normally cultivated grapevine and after UV treatment $(0.04-0.95 \mathrm{mg} / \mathrm{g}$ DW) $[30,31]$. However, the stilbene content in our experiments was lower than the stilbene content reached after the application of cyclic oligosaccharides (cyclodextrins (CDs)), separately or in combination with methyl jasmonate or some other plant stress hormones [32,33]. After using these inducing agents, only $t$-resveratrol content in the $V$. vinifera cell cultures reached $35-155 \mathrm{mg} / \mathrm{g}$ DW $[32,33]$.

It has also been shown that almost all endophytic bacteria were sensitive to antibiotics, such as gentamicin and kanamycin. Thus, it is possible to use these bacteria for the induction of stilbene production in V. amurensis cell culture. Moreover, the fungus Cladosporium sp. could be a promising supplement for the induction of stilbene biosynthesis, since it significantly activated stilbene production and was sensitive to fluconazole.

\section{Conclusions}

For the first time, this study examined the influence of the main representatives of the endophytic bacteria and fungi of wild grape $V$. amurensis on cell growth and production of resveratrol and its derivatives. The addition of endophytic bacteria increased the total stilbene content by 2.2-5.3 times, while the addition of endophytic fungi was more effective in inducing stilbene accumulation by 2.6-16.3 times. The highest content of stilbenes in the grapevine cells cocultured with the endophytic fungi was 13.63 and $13.76 \mathrm{mg} / \mathrm{g}$ of the cell dry weight (DW) after cocultivation with Biscogniauxia sp. and Didymella sp. 2, respectively. The highest content of stilbenes in the grapevine cells cocultured with the endophytic bacteria was $4.49 \mathrm{mg} / \mathrm{g}$ DW after cultivation with Xanthomonas sp. The increase in stilbene production was due to a significant activation of VaPAL and VaSTS gene expression.

Thus, cocultivation of grape cell culture with the natural endophytes of $V$. amurensis could be considered as a new natural approach for the activation of stilbene biosynthesis, which could be used for industrial production of stilbenes in grape cell cultures. The 
development and active application of such approaches would undoubtedly contribute to the transition to a highly productive and environmentally friendly agriculture.

\section{Materials and Methods}

\subsection{Plant Material}

The stems and leaves of wild-growing $V$. amurensis (excised young stems $7-8 \mathrm{~cm}$ long with three healthy leaves from 2 adult plants) were sampled from a nonprotected natural population near Vladivostok, Russia (the southern Primorsky region of the Russian Far East, longitude 43.2242327 and latitude 131.99112300). The leaves and stems were collected from two grape plants located at a distance of $1 \mathrm{~km}$ from each other. The material was collected over 3 years in June (young leaves and stems), July (mature leaves and stems), and September (leaves that have become drier and changed color) 2018-2020. Each plant sample was delivered within half an hour to a temperature of $18-23{ }^{\circ} \mathrm{C}$ to the laboratory in sterile flasks and used for endophyte isolation.

\subsection{Isolation and Identification of the Endophytic Bacteria and Fungi}

A $1.5 \mathrm{~g}$ amount of the leaf and stem tissue was washed with soap. Then, under sterile conditions, they were soaked in $75 \%$ ethanol for $2 \mathrm{~min}$ and then in $10 \%$ hydrogen peroxide solution for $1 \mathrm{~min}$ and washed 5 times with sterile water. To check the efficacy of this method of surface sterilization, $100 \mu \mathrm{L}$ of the last wash water was incubated on potato dextrose agar (PDA, Neogene, UK) for fungi and on the R2A medium for bacteria [34]. The plates were inspected for the absence of colony growth. In a sterile mortar, the leaf and stem tissue of $V$. amurensis was ground to a homogeneous state, and the juice was squeezed out. Then, $100 \mu \mathrm{L}$ of the juice was applied to Petri dishes with PDA and R2A medium. After 3 days, the colonies cultivated were picked out and transferred carefully to a new sterile plate for reculturing.

DNA of some of the distinct bacteria and fungi colonies was isolated by the hexadecyltrimethylammonium bromide (CTAB) method with modifications [35]. Bacterial $16 \mathrm{~S}$ rRNA gene sequences were amplified by universal bacterial primers for the amplification of approximately $1500 \mathrm{bp} 16 \mathrm{~S}$ PCR products (8F, 5' AGA GTT TGA TCM TGG CTC AG and 1522R, 5' AAG GAG GTG ATC CAR CCG CA) [36]. The universal primers 5' AGG AGA AGT CGT AAC AAG G and $5^{\prime}$ TCC TCC GCT TAT TGA TAT GC were used for the amplification of approximately $580 \mathrm{bp} \mathrm{ITS1} \mathrm{PCR} \mathrm{products} \mathrm{[37].} \mathrm{PCR} \mathrm{products} \mathrm{were}$ sequenced using an ABI 3130 Genetic Analyzer (Applied Biosystems, Foster City, CA, USA) according to the manufacturer's instructions. The Basic Local Alignment Search Tool (BLAST) program was used for sequence analysis. Multiple sequence alignments were performed using the Clustal X program [38]. A sequence identity of $\geq 99 \%$ is considered as a sufficient threshold value for taxonomic identification.

\subsection{Treatment of Grape Cells with Endophytic Bacteria and Fungi}

The V7 callus culture was established in 2017 from young stems of the mature $V$. amurensis plants as described [39]. A $2.0 \mathrm{~g}$ amount of V7 cell culture (each callus was weighed using an electronic balance) was cultured in $50 \mathrm{~mL}$ of liquid Murashige and Skoog-modified $\mathrm{W}_{\mathrm{B} / \mathrm{A}}$ medium supplemented with $0.5 \mathrm{mg} / \mathrm{L}$ 6-benzylaminopurine (B) and $2 \mathrm{mg} / \mathrm{L} \alpha$-naphthaleneacetic acid constantly stirring in the orbital shaker in the dark for 7 days [40]. Then, $100 \mu \mathrm{L}$ of endophytic bacterial suspension and $100 \mathrm{mg}$ of endophytic fungus were added to the flask. Endophytes were preliminarily grown in $50 \mathrm{~mL}$ of liquid media R2A for bacteria and potato dextrose media for fungi in the orbital shaker for 3 days $\left(130 \mathrm{rpm}, 23^{\circ} \mathrm{C}\right)$. Endophytes were cultivated with $\mathrm{V} 7$ grape cell culture for stilbene analysis for 3 days and for biomass evaluation for 7 days. Recultivation of the endophytic strains of bacteria and fungi was carried out once or twice before cocultivation with the grape cells. The data for stilbene and fresh biomass accumulation in the cell cultures were obtained from three independent experiments with three replicates each. 


\subsection{Total RNA Extraction, Reverse Transcription, and qRT-PCR}

RNA isolation was carried out from the week-old cell-cultured V7 with 3-day cocultivation with endophytes. Total RNA isolation was performed using the CTAB-based-based protocol [41]. Complementary DNAs were synthesized as described [42]. The reverse transcription products were then amplified by PCR and verified in the absence of DNA contamination using primers listed in Table S1. The qRT-PCRs were performed with EvaGreen Real-Time PCR (Biotium, Hayward, Berkeley Heights, NJ, USA) as described [43] using cDNAs V7 callus culture and two internal controls (GAPDH and Actin), which were selected in previous studies as relevant reference genes for real-time PCRs for grapevine [44]. The expression was calculated by the $2^{-\Delta \Delta C \mathrm{~T}}$ method [45]. All GenBank accession numbers and primers are listed in Table S1.

\subsection{High-Performance Liquid Chromatography}

The dried and powdered V7 culture samples $(100 \mathrm{mg}$ ) were extracted with $95 \% \mathrm{EtOH}$ $(2 \mathrm{~mL})$ for $2 \mathrm{~h}$ at $60^{\circ} \mathrm{C}$. After extraction, we purified them with OlimPeak syringe filters, nylon, with a pore size of $0.45 \mu \mathrm{m}$ and a diameter of $13 \mathrm{~mm}$ (Teknokroma, Barcelona, Sant Cugat del Vallés, Spain), and then used them for HPLC analysis. The measurement for each sample was repeated 3 times.

Identification and quantification of all stilbenes was performed using an HPLC LC20AD XR analytical system (Shimadzu, Japan) and commercially available standards. DAD data were recorded in the $200-500 \mathrm{~nm}$ range, and chromatograms for quantification were acquired at $310 \mathrm{~nm}$. The chromatographic separation was performed on a Shim-pack GIST C18 column ( $150 \mathrm{~mm}, 2.1 \mathrm{~nm}$ i.d., $3 \mu \mathrm{m}$ part size; Shimadzu, Japan). Extracts from cells cultures were separated using $0.1 \%$ formic acid and acetonitrile as mobile phases $\mathrm{A}$ and $\mathrm{B}$, respectively, with the following elution profile: 0 to $35 \mathrm{~min} 0 \%$ of B; 35 to $40 \mathrm{~min} 40 \%$ of $\mathrm{B} ; 40$ to $50 \mathrm{~min} 50 \%$ of $\mathrm{B} ; 50$ to $65 \mathrm{~min} 100 \%$ of $\mathrm{B}$. A $3 \mu \mathrm{L}$ volume of the sample extract was injected with a constant column temperature maintained at $40{ }^{\circ} \mathrm{C}$ and a flow rate maintained at $0.2 \mathrm{~mL} / \mathrm{min}$. The contents of stilbenes were determined by using the external standard method using the five-point regression calibration curves built with the available standards. The analytical standards trans-resveratrol, trans-piceid, and trans-piceatannol were obtained from Sigma-Aldrich (St. Louis, MO, USA), and $d$-viniferin was obtained from Panreac AppliChem (GmbH, Darmstadt, Germany). Cis isomers of resveratrol and piceid were obtained under sunlight exposure of the respective standard solution containing the trans-isomer as reported earlier [31].

\subsection{Antibiotic Susceptibility Analysis}

To analyze sensitivity to antibiotics, $100 \mu \mathrm{L}$ of a suspension of endophytic bacteria and $1 \mathrm{~cm}^{2}$ of endophytic fungi were placed on Petri dishes with agar culture media R2A for bacteria and PDA for fungi [22]. Paper disks $1 \mathrm{~cm}$ in diameter soaked in antibiotic solution were placed on top. Antibiotic concentrations were ampicillin- $50 \mathrm{mg} / \mathrm{L}$, chloramphenicol— $35 \mathrm{mg} / \mathrm{L}$, cefotaxime — $250 \mathrm{mg} / \mathrm{L}$, gentamicin— $50 \mathrm{mg} / \mathrm{L}$, kanamycin— $50 \mathrm{mg} / \mathrm{L}$, rifampicin $-50 \mathrm{mg} / \mathrm{L}$, spectinomycin $-150 \mathrm{mg} / \mathrm{L}$, and tetracycline $-40 \mathrm{mg} / \mathrm{L}$. A similar method was used to analyze the sensitivity of endophytes to resveratrol at concentrations of $1 \mathrm{mM}$.

\subsection{Statistical Analysis}

The data are presented as mean \pm standard error (SE) and were tested by Student's $t$-test. The 0.05 level was selected as the point of minimal statistical significance in all analyses. Three independent experiments were performed for each type of experiment.

Supplementary Materials: The following are available online at https:/ /www.mdpi.com/article/10 .3390/plants10071276/s1, Table S1: Primers used in PCR and qRT-PCR amplification. The sequences of $16 S$ rRNA (bacteria) or ITS1 (fungi) of microorganisms used in experiments isolated from Vitis amurensis grape microbiome. 
Author Contributions: O.A.A. and K.V.K. performed research design, data analysis, paper preparation, and experimental process. N.N.N. performed isolation DNA of microorganism, PCR, and sequencing analysis. O.A.A. performed qRT-PCRs. A.R.S. performed HPLC analyses. A.S.D. performed paper preparation. All authors have read and agreed to the published version of the manuscript.

Funding: This work was supported by a grant from the Russian Science Foundation (grant number 20-74-00002).

Data Availability Statement: The data presented in this study are available within the article and Supplementary Material.

Conflicts of Interest: The authors declare no conflict of interest.

\section{References}

1. Nair, D.N.; Padmavathy, S. Impact of Endophytic Microorganisms on Plants, Environment and Humans. Hindawi Publ. Corpor. Sci. World J. 2014, 2014, 250693. [CrossRef]

2. Salvetti, E.; Campanaro, S.; Campedelli, I.; Fracchetti, F.; Gobbi1, A.; Tornielli, G.B.; Torriani, S.; Felis, G.E. Whole-metagenomesequencing based community profiles of Vitis vinifera L. cv. Corvina berries withered in two post-harvest conditions. Front. Microbiol. 2016, 7, 937. [CrossRef]

3. Jayawardena, R.S.; Purahong, W.; Zhang, W.; Wubet, T.; Li, X.H.; Liu, M.; Zhao, W.; Hyde, K.D.; Liu, J.H.; Yan, J. Biodiversity of fungi on Vitis vinifera L. revealed by traditional and high-resolution culture-independent approaches. Fun Diver. 2018, 90, 1-84. [CrossRef]

4. Gamalero, E.; Bona, E.; Novello, G.; Boatti, L.; Mignone, F.; Massa, N.; Cesaro, P.; Berta, G.; Lingua, G. Discovering the bacteriome of Vitis vinifera cv. Pinot Noir in a conventionally managed vineyard. Sci. Rep. 2020, 10, 6453. [CrossRef]

5. Campisano, A.; Pancher, M.; Puopolo, G.; Puddu, A.; Lopez-Fernandez, S.; Biagini, B.; Yousaf, S.; Pertot, I. Diversity in endophyte populations reveals functional and taxonomic diversity between wild and domesticated grapevines. Am. J. Enol. Vitic. 2015, 66, 12-21. [CrossRef]

6. Andreolli, M.; Lampis, S.; Zapparoli, G.; Angelini, E.; Vallini, G. Diversity of bacterial endophytes in 3- and 15-year-old grapevines of Vitis vinifera cv. Corvina and their potential for plant growth promotion and phytopathogen control. Microb. Res. 2016, 183, 42-52. [CrossRef]

7. Theocharis, A.; Bordiec, S.; Fernandez, O.; Paquis, S.; Dhondt-Cordelier, S.; Baillieul, F.; Clément, C.; Barka, E.A. Burkholderia phytofirmans PsJN primes Vitis vinifera L. and confers a better tolerance to low nonfreezing temperatures. Mol. Plant Microbe Interact. 2012, 25, 241-249. [CrossRef] [PubMed]

8. Verhagen, B.; Trotel-Aziz, P.; Jeandet, P.; Baillieul, F.; Aziz, A. Improved resistance against Botrytis cinerea by grapevine-associated bacteria that induce a prime oxidative burst and phytoalexin production. Phytopathology 2011, 101, 768-777. [CrossRef] [PubMed]

9. Yu, M.; Chen, L.C.; Qu, J.Z.; Liu, F.; Zhou, M.; Ma, Y.M.; Xiang, S.Y.; Pan, X.X.; Zhang, H.B.; Yang, M.Z. Exposure to endophytic fungi quantitatively and compositionally alters anthocyanins in grape cells. Plant Physiol. Biochem. 2020, 149, 144-152. [CrossRef] [PubMed]

10. Yang, M.Z.; Huang, L.H.; Ao, X.J.; Ren, A.Y.; Yuan, M.Q.; Zhang, H.B. Endophytic fungal strains specifically modified the biochemical status of grape cells. J. Plant Biol. 2018, 61, 210-216. [CrossRef]

11. Chen, Q.; Diao, L.; Song, H.; Zhu, X. Vitis amurensis Rupr: A review of chemistry and pharmacology. Phytomedicine 2018, 49, 111-122. [CrossRef]

12. Wang, Y.; Xin, H.; Fan, P.; Zhang, J.; Liu, Y.; Dong, Y.; Wang, Z.; Yang, Y.; Zhang, Q.; Ming, R.; et al. The genome of Shanputao (Vitis amurensis) provides a new insight into cold tolerance of grapevine. Plant J. 2021, 105, 1495-1506. [CrossRef] [PubMed]

13. Wu, J.; Zhang, Y.; Zhang, H.; Huang, H.; Folta, K.; Lu, J. Whole genome wide expression profiles of Vitis amurensis grape responding to downy mildew by using Solexa sequencing technology. BMC Plant Biol. 2010, 10, 234. [CrossRef] [PubMed]

14. Liu, L.; Li, H. Research progress in amur grape, Vitis amurensis Rupr. Can. J. Plant Sci. 2013, 93, 565-575. [CrossRef]

15. Yim, N.; Ha, T.; Trung, T.; Kim, J.; Lee, S.; Na, M.; Jung, H.; Kim, H.; Kim, Y.; Bae, K. The antimicrobial activity of compounds from the leaf and stem of Vitis amurensis against two oral pathogens. Bioorg. Med. Chem. Lett. 2010, 20, 1165-1168. [CrossRef]

16. Wang, C.; Ai, J.; Liu, Y.; Lv, H.; Fan, S.; Yang, Y. Fusarium avenaceum: A New Pathogen Causing Amur Grape (Vitis amurensis) Fruit Rot in Jilin Province, China. Plant Dis. 2015, 99, 889. [CrossRef]

17. Li, Z.; Chang, P.; Gao, L.; Wang, X. The Endophytic Fungus Albifimbria verrucaria from Wild Grape as an Antagonist of Botrytis cinerea and Other Grape Pathogens. Phytopathology 2020, 110, 843-850. [CrossRef]

18. Chong, J.; Poutaraud, A.; Hugueney, P. Metabolism and roles of stilbenes in plants. Plant Sci. 2009, 177, 143-155. [CrossRef]

19. Kiselev, K.V. Perspectives for production and application of resveratrol. Appl. Microbiol. Biotechnol. 2011, 90, 417-425. [CrossRef] [PubMed]

20. Suwalsky, M.; Villena, F.; Gallardo, M.J. In vitro protective effects of resveratrol against oxidative damage in human erythrocytes. Biochim. Biophys. Acta Biomembr. 2015, 1848, 76-82. [CrossRef] 
21. Jeandet, P.; Douillet-Breuil, A.C.; Bessis, R.; Debord, S.; Sbaghi, M.; Adrian, M. Phytoalexins from the Vitaceae: Biosynthesis, Phytoalexin Gene Expression in Transgenic Plants, Antifungal Activity, and Metabolism. J. Agric. Food Chem. 2002, 50, $2731-2741$. [CrossRef] [PubMed]

22. Jorgensen, J.H.; Ferraro, M.J. Antimicrobial Susceptibility Testing: A Review of General Principles and Contemporary Practices. Med. Microbiol. 2009, 49, 1749-1755. [CrossRef]

23. Ma, D.S.L.; Tan, L.T.H.; Chan, K.G.; Yap, W.H.; Pusparajah, P.; Chuah, L.H.; Ming, L.C.; Khan, T.M.; Lee, L.H.; Goh, B.H. Resveratrol-Potential Antibacterial Agent against Foodborne Pathogens. Front. Pharmacol. 2018, 9, 102. [CrossRef] [PubMed]

24. Huang, L.H.; Yuan, M.Q.; Ao, X.J.; Ren, A.Y.; Zhang, H.B.; Yang, M.Z. Endophytic fungi specifically introduce novel metabolites into grape flesh cells in vitro. PLoS ONE 2018, 13, e0196996. [CrossRef] [PubMed]

25. Ramirez-Suero, M.; Bénard-Gellon, M.; Chong, J.; Laloue, H.; Stempien, E.; Abou-Mansour, E.; Fontaine, F.; Larignon, P.; MazetKieffer, F.; Farine, S. Extracellular compounds produced by fungi associated with Botryosphaeria dieback induce differential defence gene expression patterns and necrosis in Vitis vinifera cv. Chardonnay cells. Protoplasma 2014, 251, 1417-1426. [CrossRef]

26. Dubrovina, A.S.; Kiselev, K.V. Regulation of stilbene biosynthesis in plants. Planta 2017, 346, 597-623. [CrossRef]

27. Ku, K.L.; Chang, P.S.; Cheng, Y.C.; Lien, C.Y. Production of stilbenoids from the callus of Arachis hypogaea: A novel source of the anticancer compound piceatannol. J. Agric. Food. Chem. 2005, 53, 3877-3881. [CrossRef]

28. Yang, M.H.; Kuo, C.H.; Hsieh, W.C.; Ku, K.L. Investigation of microbial elicitation of trans-resveratrol and trans-piceatannol in peanut callus led to the application of chitin as a potential elicitor. J. Agric. Food. Chem. 2010, 58, 9537-9541. [CrossRef]

29. Xu, A.; Zhan, J.C.; Huang, W.D. Effects of ultraviolet C, methyl jasmonate and salicylic acid, alone or in combination, on stilbene biosynthesis in cell suspension cultures of Vitis vinifera L. cv. Cabernet Sauvignon. Plant Cell Tissue Organ Cult. 2015, 122, 197-211. [CrossRef]

30. Larronde, F.; Gaudillère, J.P.; Krisa, S.; Decendit, A.; Deffieux, G.; Mérillon, J.M. Airborne methyl jasmonate induces stilbene accumulation in leaves and berries of grapevine plants. Am. J. Enol. Viti. 2003, 54, 60-63.

31. Kiselev, K.V.; Aleynova, O.A.; Grigorchuk, V.P.; Dubrovina, A.S. Stilbene accumulation and expression of stilbene biosynthesis pathway genes in wild grapevine Vitis amurensis Rupr. Planta 2017, 245, 151-159. [CrossRef] [PubMed]

32. Belchí-Navarro, S.; Almagro, L.; Sabater-Jara, A.B.; Fernández-Pérez, F.; Bru, R.; Pedreño, M.A. Induction of trans-resveratrol and extracellular pathogenesis-related proteins in elicited suspension cultured cells of Vitis vinifera cv Monastrell. J. Plant Physiol. 2013, 170, 258-264. [CrossRef] [PubMed]

33. Almagro, L.; Belchi-Navarro, S.; Martinez-Marquez, A.; Bru, R.; Pedreno, M.A. Enhanced extracellular production of transresveratrol in Vitis vinifera suspension cultured cells by using cyclodextrins and coronatine. Plant Physiol. Biochem. 2015, 97, 361-367. [CrossRef] [PubMed]

34. Reasoner, D.J.; Geldreich, E.E. A new medium for the enumeration and subculture of bacteria from potable water. Appl. Environ. Microbiol. 1985, 49, 1-7. [CrossRef] [PubMed]

35. Kiselev, K.V.; Ageenko, N.V.; Kurilenko, V.V. Involvement of the cell-specific pigment genes pks and sult in the bacteria defense response of the sea urchin Strongylocentrotus intermedius. Dis. Aquat. Org. 2013, 103, 121-132. [CrossRef]

36. Lane, D.J. 16S/23S rRNA Sequencing. In Nucleic Acid Techniques in Bacterial Systematic; Stackebrandt, E., Goodfellow, M., Eds.; John Wiley and Sons: New York, NY, USA, 1991; pp. 115-175.

37. White, T.J.; Bruns, T.; Lee, S.; Taylor, J. Amplification and direct sequencing of fungal ribosomal RNA genes for phylogenetics. In PCR Protocols: A Guide to Methods and Applications; Academic Press, Inc.: Cambridge, MA, USA, 1990; pp. 315-322.

38. Altschul, S.F.; Gish, W.; Miller, W.; Myers, E.W.; Lipman, D.J. Basic Local Aligment Search Tool. J. Mol. Biol. 1990, 3, 403-410. [CrossRef]

39. Tyunin, A.P.; Suprun, A.R.; Nityagovsky, N.N.; Manyakhin, A.Y.; Karetin, Y.A.; Dubrovina, A.S.; Kiselev, K.V. The effect of explant origin and collection season on stilbene biosynthesis in cell cultures of Vitis amurensis Rupr. Plant Cell Tiss. Organ Cult. 2019, 136, 189-196. [CrossRef]

40. Dubrovina, A.S.; Kiselev, K.V. Effect of long-term cultivation on resveratrol accumulation in a high-producing cell culture of Vitis amurensis. Acta Physiol. Plant. 2012, 34, 1101-1106. [CrossRef]

41. Kiselev, K.V.; Aleynova, O.A.; Tyunin, A.P. Expression of the R2R3 MYB transcription factors in Vitis amurensis Rupr. plants and cell cultures with different resveratrol content. Russ. J. Genet. 2017, 53, 465-471. [CrossRef]

42. Kiselev, K.V.; Dubrovina, A.S.; Shumakova, O.A.; Karetin, Y.A.; Manyakhin, A.Y. Structure and expression profiling of a novel calcium-dependent protein kinase gene, CDPK3a, in leaves, stems, grapes, and cell cultures of wild-growing grapevine Vitis amurensis Rupr. Plant Cell Rep. 2013, 32, 431-442. [CrossRef]

43. Dubrovina, A.S.; Kiselev, K.V.; Khristenko, V.S.; Aleynova, O.A. VaCPK20, a calcium-dependent protein kinase gene of wild grapevine Vitis amurensis Rupr., mediates cold and drought stress tolerance. J. Plant Physiol. 2015, 185, 1-12. [CrossRef] [PubMed]

44. Reid, K.E.; Olsson, N.; Schlosser, J.; Peng, F.; Lund, S.T. An optimized grapevine RNA isolation procedure and statistical determination of reference genes for real-time RT-PCR during berry development. BMC Plant Biol. 2006, 6, 27. [CrossRef] [PubMed]

45. Livak, K.J.; Schmittgen, T.D. Analysis of relative gene expression data using real-time quantitative PCR and the 2(-Delta Delta (T)) method. Methods 2001, 25, 402-408. [CrossRef] [PubMed] 